\title{
Uma discussão teórica acerca do currículo e deficiência: Implicações para concepções e práticas de ensino
}

A theoretical discussion about curriculum and disability: Implications for teaching conceptions and practices

Una discusión teórica sobre el currículo y la discapacidad: Implicaciones para las concepciones y prácticas docentes

Tainara da Silva Ferreira ORCID: https://orcid.org/0000-0001-6205-6817 Universidade do Estado da Bahia, Brasil E-mail: thaysilva296@gmail.com

Marcia Torres Neri Soares ORCID: https://orcid.org/0000-0001-5453-7872 Universidade do Estado da Bahia, Brasil E-mail: profa.marciatorres@gmail.com

\begin{abstract}
Resumo
Este artigo objetiva discutir modos de organização curricular em atenção às necessidades de estudantes com deficiência, transtornos globais do desenvolvimento e altas habilidades/superdotação, público alvo da educação especial, com o foco nas concepções e práticas de ensino. Para tanto, baseia-se em uma metodologia de estado da arte sobre currículo e educação especial relativa ao intervalo de 2015-2019 na Biblioteca Digital Brasileira de Teses e Dissertações (BDTD). O levantamento teórico, oriundo de pesquisa de Iniciação Científica da Universidade do Estado da Bahia (2019-2020), coopera para o entendimento acerca de um currículo comum e acessível a todos estudantes e suas reverberações nas práticas de ensino para turmas inevitavelmente heterogêneas, principalmente na concepção de deficiência basilar para o engendramento destas práticas. No tocante às categorias identificadas na pesquisa a) concepção ampla e b) concepção individualizada, nota-se a separação do seguinte quantitativo: do total de 32 estudos analisados, 7 trabalhos baseiam-se na concepção ampla e 25 trabalhos são calcados na concepção individualizada. A prevalência de estudos na perspectiva de uma concepção curricular individualizada desperta atenção e, sob os aspectos balizados neste texto, indicam a importância da ampliação da ideia de um mesmo currículo acessível a quaisquer estudantes. Indubitavelmente, a divulgação do estudo pode favorecer ao campo da inclusão do público alvo da educação especial, especialmente por inspirar futuras pesquisas e experiências para a garantia dessa inclusão escolar.
\end{abstract}

Palavras-chave: Currículo escolar; Deficiência; Educação especial.

\begin{abstract}
This article aims to discuss ways of curricular organization in attention to the needs of students with disabilities, global developmental disorders, and high skills/giftedness, target audience of special education, with a focus on teaching concepts and practices. To this end, it is based on a state-of-the-art methodology on curriculum and special education regarding the 2015-2019 interval at the Brazilian Digital Library of Theses and Dissertations (BDTD). The theoretical survey, derived from Scientific Initiation research at the Universidade do Estado da Bahia (2019-2020), cooperates for the understanding about a common and accessible curriculum for all students and its reverberations in teaching practices for inevitably heterogeneous classes, mainly in the conception of basic deficiency for the engendering of these practices. Regarding the categories identified in the research a) broad conception and b) individualized conception, it is noted the separation of the following quantitative: of the total of 32 studies analyzed, 7 studies are based on the broad conception and 25 works are based on the individualized conception. The prevalence of studies from the perspective of an individualized curricular concept arouses attention and, under the aspects marked out in this text, indicate the importance of expanding the idea of the same curriculum accessible to any students. Undoubtedly, the dissemination of the study can favor the field of inclusion of the target audience of special education, especially because it inspires future research and experiences to guarantee this school inclusion.
\end{abstract}

Keywords: School curriculum; Disability; Special education.

\section{Resumen}

Este artículo tiene como objetivo discutir las formas de organización curricular en la atención a las necesidades de estudiantes con discapacidad, trastornos globales del desarrollo y altas habilidades/superdotación, público objetivo de 
educación especial, centrado en los conceptos y prácticas educativas. Para ello, se basa en una metodología de estado del arte sobre currículo y educación especial para el intervalo 2015-2019 en la Biblioteca Digital Brasileña de Tesis y Disertaciones (BDTD). El análisis teórico, proveniente de la investigación de Iniciación Científica en la Universidad del Estado de Bahía (2019-2020), colabora para el entendimiento de un currículo común y accesible para todos los estudiantes y sus reverberaciones en las prácticas docentes para clases inevitablemente heterogéneas, principalmente en la concepción de deficiencia basilar para la generación de estas prácticas. Con respecto a las categorías identificadas en la investigación a) concepción amplia y b) concepción individualizada, se observa la separación de los siguientes datos cuantitativos: del total de 32 estudios analizados, 7 estudios se basan en la concepción amplia y 25 trabajos se basan sobre la concepción individualizada. El predominio de estudios en la perspectiva de una concepción curricular individualizada llama la atención y, bajo los aspectos considerados en este texto, señalan la importancia de ampliar la idea de un mismo currículo accesible a cualquier estudiante. Sin duda, la difusión del estudio puede favorecer al campo de inclusión del público objetivo de la educación especial, sobre todo porque inspira futuras investigaciones y experiencias para garantizar esta inclusión escolar.

Palabras clave: Currículo escolar; Discapacidad; Educación especial.

\section{Introdução}

Concepções de educação especial e currículo escolar há muito povoam a atenção de diferentes estudiosos no campo da educação (Carvalho, 2008; Klein; Formoso, 2009, Lopes, 2010; Silva, 2010; Effgen, 2011; Fonseca, 2014; Vieira, 2012; Fiorini; Deliberato; Manzini, 2013; Leite; Martins, 2015; Zanato; Gimenes, 2017). O interesse vertiginoso, assim como o olhar aguçado sobre nossas próprias dúvidas acerca de como promover condições de participação de diferentes estudantes à luz da perspectiva curricular, inspiram a construção do presente texto.

Com efeito, o estudo resulta de pesquisa de Iniciação Científica (IC) realizada entre os anos de 2019 e 2020 com o apoio do Programa Institucional de Iniciação Científica (PCIN) da Universidade do Estado da Bahia (UNEB). Assim, o objetivo central deste texto é, com base em levantamento teórico sobre currículo e educação especial publicado no intervalo de 2015-2019 na Biblioteca Digital Brasileira de Teses e Dissertações (BDTD), discutir modos de organização curricular em atenção às necessidades de estudantes público alvo da educação especial - pessoas com deficiência, transtornos globais do desenvolvimento e altas habilidades/superdotação (Brasil, 2008) -, com o foco nas concepções e práticas de ensino.

Desse modo, compreendemos a educação como mote para formação de indivíduos sob a valorização de suas capacidades, êxito e participação equitativa ao convívio social. Do ponto de vista legal, a Constituição Federal de 1988 (Brasil, 1988) no artigo 205 define a educação como um direito de todos. Ao garantir o pleno desenvolvimento da pessoa, o exercício da cidadania e a qualificação para o trabalho, o texto legal estabelece a igualdade de condições de acesso e permanência na escola como um princípio.

Do ponto de vista histórico, pessoas com deficiência foram consideradas inferiores e, de diferentes modos, excluídas dos meios sociais. Segundo Ferreira e Guimarães (2003), a deficiência, antigamente, era vista a partir de crenças sobrenaturais, demoníacas e supersticiosas. Tais pessoas sofriam rejeição, não podendo usufruir do convívio social, pois eram julgadas indignas de vários direitos, incluindo o da escolarização. Todavia as políticas mais atuais (Brasil, 2008; 2015) têm assegurado modos de garantia da inclusão de estudantes público alvo da educação especial com base no princípio de aprendizagem para todos.

Definida como uma modalidade da educação (Brasil, 1996) a educação especial se incube de versar sobre condições de participação de seu público alvo em uma educação igualitária, buscando atender às necessidades individuais e coletivas, com a premissa de respeito às singularidades e especificidades de cada um.

Discutir a educação especial sob a perspectiva do currículo lograda neste texto pode ser de grande relevância em diferentes dimensões: I. possibilidade de ampliação das discussões à luz do olhar dos leitores e/ou pesquisadores do campo de estudos, bem como de quaisquer estudantes e professores a despeito de ainda não terem trabalhado com o público da educação especial; II. fortalecimento das pesquisas da área, haja vista oportunizar um fecundo levantamento com base na produção bibliográfica entre os anos de 2015-2019; III. Contribuições com a vida acadêmica de estudantes em formação face às 
possibilidades da IC como ferramenta de apropriação de temas complexos e necessários ao contexto prático de diferentes profissionais; IV. oportunidade em discutir, do ponto de vista das práticas de ensino, as concepções subjacentes ao trabalho com estudantes público alvo da educação especial e, desse modo, inspirar futuras experiências para/na garantia da inclusão escolar.

O trabalho de origem do estudo, baseia-se em um "estado da arte" (Ferreira, 2002), entendido como a assunção do desafio discutir e mapear uma produção acadêmica em diferentes campos do conhecimento sob o ponto de vista dos aspectos e dimensões privilegiados em diversos contextos científicos.

Tendo em vista sua organização, o texto encontra-se dividido em seções. Esta seção introdutória principia a apresentação do tema e sua inserção no quadro de relevância das produções acadêmicas, principalmente do detalhamento da educação especial no bojo das propostas legais brasileiras. Em seguida, abordamos os Subsídios teóricos: currículo escolar e deficiência, com o fito de discutir amplamente o substrato teórico de base para a discussão pretendida. A ênfase à deficiência justifica-se pela preponderância de sua concepção ser determinante para o modo como a educação especial se revelou/revela em diferentes propostas educacionais. Desse modo, na seção Métodos e Resultados: um olhar sobre o tema discutimos a metodologia utilizada na construção dos dados, bem como os principais resultados do estudo até compartilhar nossas Considerações Finais em forma de arremates sobre o diálogo com as principais contribuições do estudo. A seguir, iniciamos com as interlocuções teóricas de sustentação do texto.

\section{Subsídio Teórico: Currículo Escolar e Deficiência}

A centralidade do currículo na esfera educacional decorre, em grande parte, deste se constituir o alicerce responsável pela interlocução de um planejamento e concepções subjacentes a uma estrutura compatível (ou não!) a um ambiente de respeito e de igualdade para todos. Na perspectiva cunhada por Sacristán (2000, p. 30) "[...] O interesse pelo currículo segue paralelo com o interesse por conseguir um conhecimento mais penetrante sobre a realidade escolar". Indagar sobre como a prática de ensino se sustenta, sugere-nos olhar para o currículo à luz de diferentes contribuições teóricas.

O currículo escolar, portanto, atento às especificidades dos estudantes, deve agregar a reflexão como eixo de sua consecução, por isso importa reconhecer neste artefato, suas intencionalidades.

O currículo não é um elemento inocente e neutro de transmissão desinteressada do conhecimento social. O currículo está implicado em relações de poder, o currículo transmite visões sociais particulares e interessadas, o currículo produz identidades individuais e sociais particulares. O currículo não é um elemento transcendente e atemporal - ele tem uma história, vinculada a formas específicas e contingentes de organização da sociedade e da educação. (Moreira; Silva, 1995, p. 7-8).

O currículo se estabelece nas interlocuções do cotidiano escolar, no manejo das práticas de ensino. Se este ou aquele conteúdo, quem está apto ou não para determinada atividade, quem pode ou não alcançar um objetivo, como promover condições mais equânimes de participação, quais os recursos ou estratégias para tornar os conteúdos acessíveis à toda turma, quem são os elegíveis a promoção ou retenção no contexto avaliativo (...), estas e outras tantas decisões/inquietações permeiam o fazer pedagógico de diferentes professores em contextos diversos e, conquanto acreditemos nas infinitas possibilidades dos estudantes, persistem entre alguns, ideias sobre os inelegíveis para as aprendizagens.

Desse modo, o currículo não pode ser desvinculado das condições de trabalho e formação docentes, sua simetria com as práticas precisa ser investigada para o devido reconhecimento de suas intencionalidades na constituição das propostas de ensino. Sob a perspectiva de base para nossas análises na pesquisa a ser apresentada, o currículo tem participação direta na projeção de identidades, construção da realidade "[...] tudo isso produzindo sentidos. Trata-se, portanto, de um discurso 
produzido na interseção entre diferentes discursos sociais e culturais que, ao mesmo tempo, reitera sentidos postos por tais discursos e o recria" (Lopes; Macedo, 2011, p. 41).

No tocante às suas reverberações em uma proposta inclusiva, o currículo necessita ser acessível se atentando às características dos diferentes sujeitos e estar sempre em modificação. Para Effgen (2011) o currículo deve ser comum aos estudantes e tomar por base o princípio da inclusão sob articulações com o Atendimento Educacional Especializado (AEE).

Embora reconheçamos a importância do AEE como elo entre sala comum e o acompanhamento especializado requerido por considerável quantitativo de estudantes, destacamos essa realidade não ter alcançado todas as escolas brasileiras, assim como considerarmos ser a sala comum, mesmo na ausência deste apoio, responsável pela/na organização de práticas de ensino voltadas a todos os estudantes, sem secundarizar a aprendizagem, tampouco delegar ao profissional do AEE a responsabilidade exclusiva por seu desenvolvimento. Além dos aspectos ponderados, consideramos também "o esvaziamento pedagógico/epistemológico por meio da formação aligeirada para o AEE" como indicam Carvalho e Antunes (2021, p. 11).

Segundo Sacristán (2000. p. 21) "entender o currículo num sistema educativo requer prestar atenção às práticas políticas e administrativas". Ou seja, ambas precisam de organização e planejamento, pois são essenciais para a elaboração de um currículo e a busca de um suporte para o desenvolvimento da escola na perspectiva inclusiva.

O currículo é o objeto de muitas práticas e se expressa e concretiza nelas, se molda numa multidão de contextos, sendo afetado por forças sociais, por marcos organizativos, pelos sistemas de produção de materiais didáticos, pelo ambiente da aula, pelas práticas pedagógicas cotidianas, pelas práticas de avaliação, concluindo que todo ele é um processo social (Sacristán, 1998, p. 165).

Como processo social, o currículo se encarrega de dar sentido às propostas educativas em sua finalidade e correspondência a fixação ou transposição das desigualdades educacionais. Por isso, elegemos a deficiência e sua concepção como fulcrais aos debates pretendidos neste texto.

Comumente, a deficiência é vista como algo fora do normal, ou seja, distante de um padrão social aceitável e, por isso, vítima de preconceito, discriminação e desigualdades de toda ordem. Sua compreensão, contudo, depende da concepção basilar de sua construção. Nesse caso, "a deficiência não é mais uma simples expressão de uma lesão que impõe restrições a participação social de uma pessoa. Deficiência é um conceito complexo que reconhece o corpo com lesão, mas que também denuncia a estrutura social que oprime a pessoa" (Diniz, 2007, p. 09).

Transcendendo ao modelo médico de culpabilização pelo corpo deficiente, a concepção social da deficiência ajuda a desvincular as características de (in)capacidades dos sujeitos de suas condições físicas para compreendê-las sob o ponto de vista das condições sociais disponibilizadas em um dado contexto.

Conforme Magalhães $(2002$, p. 1) "o status social de deficiente faz recair sobre o indivíduo um olhar pejorativo que enfatiza suas dificuldades em detrimento de suas possibilidades de desenvolvimento e aprendizagem", ou seja, as pessoas ao olharem um indivíduo com deficiência, acabam julgando como incapaz de fazer algo. Ainda é possível constatar a triste realidade no espaço escolar, pois muitas vezes o estudante conquista o direito de estar, porém persistem a baixa expectativa e a participação quase nula nas atividades propostas pela/na escola.

A inclusão de estudantes público alvo da educação especial revela a necessidade de superação de sua inclusão física, ou das condições de acesso ao espaço escolar, ampliadas sob a perspectiva de mudança de lógica, de postura pedagógica, da organização da escola (seus tempos e espaços) e do currículo escolar para a educação inclusiva cumprir seu objetivo educativo.

[...], organizar a escola, os tempos e os conhecimentos, o que ensinar e aprender respeitando a especificidade de cada tempo de formação não é uma opção a mais na diversidade de formas de organização escolar e curricular, é uma exigência do direito que os educandos têm a ser respeitados em seus tempos mentais, culturais, éticos, humanos. (Arroyo, 2007, p. 45- 46). 
A concepção da deficiência sob o modelo social (Diniz, 2007) deve orientar as práticas primando pelo respeito à diversidade e diferenças de seus estudantes. Nesse sentido, o currículo não deve estar circunscrito somente aos conteúdos, mas buscar fazer uma relação entre estes com a realidade dos estudantes, sua cultura, seu modo de viver, suas experiências, dentre outros aspectos cruciais na formação do sujeito para viver em sociedade.

Para Gomes (2007), numa perspectiva ampliada da discussão, nas últimas décadas aconteceram muitos avanços nas políticas de inclusão com convergência para a desconstrução do imaginário negativo sobre as diferenças a partir de práticas significativas de educação inclusiva. A afirmação da autora, atrelada aos objetivos do presente texto, permite-nos olhar para a pesquisa desenvolvida com mais cuidado, como faremos no seguimento.

\section{Métodos e Resultados: um Olhar Sobre o Tema}

O aporte metodológico utilizado é de cunho qualitativo de preponderância de aspectos não quantificáveis da realidade. Centra-se na compreensão e explicação da dinâmica das relações sociais. Para Minayo (2001, p. 21) a pesquisa qualitativa "trabalha com o universo de significados, motivos, aspirações, crenças, valores e atitudes, o que corresponde a um espaço mais profundo das relações, dos processos e dos fenômenos que não podem ser reduzidos à operacionalização de variáveis.”

A pesquisa das dissertações e teses referentes ao Estado da Arte (Ferreira, 2002) doravante compartilhado foi realizada exclusivamente em meio eletrônico, equivalente ao período compreendido entre os anos 2015 e 2019. Como resultado inicial identificou-se um total de 504 trabalhos catalogados.

A primeira etapa desse levantamento foi realizada a partir de consultas ao banco de teses e dissertações online da BDTD. Este banco permite uma pesquisa diversificada e/ou alternativa por título, autor, assunto, assim como oferece como filtros instituições renomadas no âmbito do ensino superior brasileiro.

O levantamento realizado partiu da utilização do campo referente ao assunto - especificado no item "todos os campos" - e tendo como filtros o ano de defesa (a partir de 2015) e a área de conhecimento (Ciências Humanas). Os descritores utilizados, currículo escolar e educação especial, foram informados de modo aglutinado para o acesso na busca do levantamento da pesquisa. A demarcação do interesse central permitiu maior sucesso para os objetivos assumidos desde o projeto de elaboração da pesquisa denominada "Concepções de Educação Especial e Currículo Escolar: um olhar sobre a produção da Biblioteca Digital Brasileira de Teses e Dissertações".

Apesar de localizar um número suficiente de trabalhos significativos sobre o objeto de estudo, ocorreram algumas dificuldades principalmente no tocante aos downloads dos textos. Alguns não ofereceram a liberação para baixar, mostrando somente o resumo, mas isso não impediu a análise desses trabalhos tendo em vista a leitura do texto completo só ter sido requerida face a incongruência de resumos cujo conteúdo deixou dúvidas a respeito da temática discutida na dissertação ou tese e sua vinculação ao nosso objeto de estudo.

Alguns trabalhos também não oportunizaram a opção de baixar o resumo. Isso cooperou, em uma primeira análise, ao seu descarte, todavia houve a necessidade de voltar ao banco para contatar a possibilidade de ler o resumo sem precisar fazer o download do trabalho, estratégia revelada como positiva. Quanto aos textos realmente descartados, estes não tinham os descritores no Resumo e palavras-chave e não apresentaram relação direta com a investigação.

A análise de dados (Bardin, 2009), portanto, ocorreu em 3 etapas. A primeira foi a pré-análise, constituída pelo primeiro contato com as teses e dissertações para a realização pesquisa, assim acontecendo o download dos trabalhos encontrados a partir dos descritores utilizados e posteriormente submetidos para análise. Após os trabalhos salvos ocorreu sua separação por pasta e ano.

A segunda foi a exploração dos trabalhos, analisando e selecionando os textos pertinentes à pesquisa por meio de tabelas de controle da pesquisadora iniciante, nas quais tinham a classificação por ano, autor e quanto à contribuição a) concepção ampla 
e b) concepção individualizada. As denominadas: concepção ampla e concepção individualizada foram as categorias norteadoras do estudo e podem ser entendidas, respectivamente, como a) propostas curriculares centradas na concepção ampla de currículo suficiente para advogar em torno de um mesmo currículo para todos os estudantes, com e sem deficiência e b) trabalhos cuja concepção curricular favorecem a ideia de um currículo individualizado ou adaptado em atenção às necessidades específicas de estudantes com deficiência.

Nesta etapa, os trabalhos descartados por não fazerem parte da pesquisa, foram colocados em uma pasta separados por ano. O cuidado implicou avaliar de modo detalhado sua relação ou não com o objeto de estudo elucidado, bem como analisar os textos sobrantes quanto aos objetivos e centralidade, este último aspecto a ser esmiuçado em outros trabalhos. A terceira etapa foi o processo de análise, trazendo as contribuições dos autores para o trabalho, quanto ao currículo comum ou adaptado para estudantes público alvo da educação especial.

Reiteradamente, para construção dos dados dessa pesquisa, utilizamos os descritores da base de consulta: educação especial e currículo escolar. Ao todo, como dantes mencionado, foram encontrados 504 trabalhos aparentemente relacionados ao tema assim distribuídos: 103 em 2015, 116 em 2016, 125 em 2017, 117 em 2018 e 43 em 2019. Estes números foram refinados conforme comprovam as publicações aqui socializadas.

O decréscimo no ano de 2019, desperta-nos atenção, conquanto não seja alvo do objetivo do texto, parece dar indício sobre a necessidade de novas pesquisas cujo fulcro permita entender o dado como avanço no enfrentamento da discussão curricular ou substituição por outros temas mais relevantes dada a conjuntura educacional da escolarização de pessoas com deficiência, neste ano.

Dos 504 trabalhos, verificou-se apenas 116 estudos cujos resumos ou palavras-chave direcionaram para o tema currículo ou educação especial, entretanto destas somente 32 publicações dedicaram-se à interlocução entre os dois campos do conhecimento.

Com centralidade no trabalho apresentado e, tomando por base o ano de 2015, após a pré-análise, embora aparentassem relacionar-se ao tema, dos 22 trabalhos localizados, apenas 09 possuem intrínseca relação com nosso objeto. Scherer (2015) discute a perspectiva das adaptações curriculares como resultantes de movimentos nacionais e internacionais anteriores à publicação de documentos legais brasileiros normatizadores da inclusão escolar e seu marco para este movimento. Insiste na flexibilização curricular como uma importante mudança de ênfase na apropriação do discurso em pauta no âmbito da inclusão.

Já Monteiro (2015), aborda as diferentes metodologias empregadas nos processos de planejamento, avaliação e a implicação de tais estratégias na produção do chamado currículo inclusivo, ou seja, quando ocorre condições de participação no currículo para a verdadeira inclusão dos estudantes com deficiência. Para Valera (2015) com o foco na deficiência intelectual é importante compreender as adaptações e os diferentes níveis de ocorrência destas adaptações. Com base nos resultados da pesquisa, os professores não utilizam as adaptações por desconhecimento e por considerá-las um grande desafio. O levantamento da autora endossa a importância das adaptações como caminho imprescindível à inclusão escolar.

Soares (2015) defende um currículo comum a todos estudantes. Segundo a autora, mudanças nas práticas curriculares voltadas às necessidades de estudantes com deficiência promovem melhores formas de participação a todo e qualquer estudante. Costa (2015) defende as adaptações curriculares para estudantes com deficiência visual em aulas de Educação Física como contributo para efetivação do processo de inclusão e até uma forma de evitar quadros de exclusão funcional. Já Filho (2015) argumenta sobre ser imprescindível atender às necessidades sociais e linguísticas dos estudantes surdos, haja vista a falta de interação entre professor e estudante comprometer a aprendizagem.

Para Mesquita (2015), é preciso fazer uma diferenciação de atividades escolares no currículo para alcançar a inclusão e decorrente interação social, indispensável à formação de estudantes com deficiência intelectual. Aporta (2015) percebe, face a técnicas baseadas em Análise Comportamental Aplicada (ACA), grandes evidências de eficácia no Transtorno do Espectro 
Autista (TEA). Aposta na avaliação individualizada como meio de melhor desenvolvimento e desempenho dos estudantes. Marostega (2015) aborda currículos de formação de professores surdos e indica o fato de contemplarem a diversidade e não a diferença surda. Assim, o currículo deve levar em consideração a identidade do estudante e não somente olhar a sua deficiência.

Tomando por base o ano de 2016, dos 28 trabalhos localizados, apenas 4 possuem intrínseca relação com nosso objeto. Embora os demais estudos estivessem associados aos nossos descritores, seu conteúdo distanciava-se da articulação pretendida. Haas (2016) identifica o currículo como capaz de valorizar a aprendizagem significativa dos conteúdos, de modo estrito, e as relações pedagógicas construídas dentro da escola com todos os agentes escolares, de modo amplo. Já para Paula (2016), com base em um estudo de caso, o movimento de construção da adaptação curricular deve ser responsabilidade dos professores e estarem associadas aos processos de ensino e aprendizagem. Conforme Teixeira (2016) o AEE serve de complemento e suplemento ao currículo e deve ser oferecido sob forma de enriquecimento curricular. Por seu turno, Flóro (2016) identifica o currículo subsidiado pelas adaptações curriculares como prática de uma proposta de inclusão escolar.

Com base no ano de 2017, dos 27 trabalhos localizados, apenas 7 possuem intrínseca relação. Martins (2017) conclui acerca da educação física em sua perspectiva cultural contribuir no processo de escolarização das pessoas com diferenças funcionais. Carvalho (2017) discute as formas organizativas do trabalho pedagógico (a organização curricular, os tempos e os espaços escolares) e a vigilância das estratégias para participação de estudantes com e sem deficiência no espaço escolar. Por seu turno, Belusso (2017) conclama a ideia de um currículo adaptado visando a auxiliar a condução do processo de ensino e aprendizagem do estudante com deficiência.

Santos (2017) identifica ser o tipo de conhecimento alicerce do currículo responsável por negar ou não a fronteira entre a prática pedagógica e os conceitos fundamentais, os quais a escola tem a responsabilidade de garantir e promover o acesso ao conhecimento historicamente acumulado. Gavaldão (2017) alerta sobre a necessidade de um currículo a considerar as particularidades dos estudantes. Por sua vez, Machado (2017) investiga a vertente de um currículo adaptado para a socialização e escolarização do aluno com transtorno global de desenvolvimento. Outrossim, Paulino (2017) pesquisa os efeitos do co-ensino na mediação pedagógica para estudantes com cegueira congênita e também defende a concepção de um currículo adaptado.

Tomando por referência o ano de 2018, apenas 09 dos 28 trabalhos localizados, possuem intrínseca relação com nosso objeto. Bachiega (2018) advoga em torno da adequação curricular para a inclusão de estudantes com deficiência intelectual. Barbosa (2018) parte de um planejamento individualizado para o estudante com TEA, mas em consonância com o currículo comum aos demais estudantes da turma. Bergamin (2018) realça a possibilidade de enriquecimento curricular para estudantes com altas habilidades e os demais das classes comuns de ensino. Já Pio (2018) destaca os avanços nas propostas dos currículos propostos pelo sistema educacional e suas contribuições ao processo de inclusão na diversidade.

Padilha (2018) investiga a mediação dos conteúdos acadêmicos para esses alunos como possibilidade de um currículo específico em atenção às suas necessidades e potencialidades. Luiz (2018) argumenta sobre a adaptação curricular contribuir para a inclusão, haja vista a manipulação de materiais e atividades estruturadas dentro de cada especificidade dos discentes possibilitarem aquisição e o desenvolvimento de saberes ligados à Geometria. Duarte (2018) conclui sobre o acesso a um currículo enriquecido, estimular a criatividade e despertar interesse dos educandos com altas habilidades/superdotação na sala comum.

Por seu turno, Guadagnini (2018) vislumbra a adaptação curricular como estratégia educativa para facilitar e promover a aprendizagem dos alunos com deficiência intelectual. Zerbato (2018) pesquisa sobre "Desenho universal para aprendizagem na perspectiva da inclusão escolar: potencialidades e limites de uma formação colaborativa", e conclui sobre a eficácia de adaptações curriculares.

No ano de 2019, dos 11 trabalhos relacionados ao tema, foram encontrados 3 trabalhos. Araújo (2019) comprova o destaque às adaptações curriculares, estratégias e recursos utilizados por professores para tornar o currículo mais acessível às 
crianças. Outra autora de igual sobrenome, Araújo (2019) verifica a ênfase às adaptações curriculares para estudantes com deficiência intelectual, organizadas e desenvolvidas na maior parte do tempo pelos professores de apoio. E, Nunes (2019) apresenta a ideia do conceito de currículo flexível, adaptação curricular e avaliação estarem além da literatura acadêmica.

No tocante às categorias identificadas na pesquisa a) concepção ampla e b) concepção individualizada, nota-se a separação do seguinte quantitativo: do total de 32 estudos analisados, 7 trabalhos baseiam-se na concepção ampla e 25 trabalhos são calcados na concepção individualizada. A preponderância de estudos na perspectiva de uma concepção curricular individualizada, pode indicar uma tendência aos trabalhos com estudos de caso e outras metodologias interessadas na análise da participação particular dos estudantes nos contextos de ensino, por isso centradas nas adaptações curriculares, e poucas abordagens de investigação sob a ótica da organização escolar para/na promoção de condições de aprendizagem a todos os estudantes, sobremodo salvaguardando o mesmo currículo comum aos com e sem deficiência.

O dado nos chama atenção, pois embora reconheçamos as grandes contribuições das pesquisas realizadas, bem como suas implicações para as práticas de diferentes professores tendo iluminadas suas práticas para mudanças em seus planejamentos e organização curricular na atenção aos estudantes público alvo da educação especial, vimos discutindo e apostando na concepção ampla como oportunizadora e extensiva às necessidades dos demais estudantes da turma.

Esta acepção assenta-se na ideia do currículo poder, pela via de seu enriquecimento, alargar nossa compreensão sobre mudanças aparentemente específicas, mas absolutamente interessantes para outros estudantes sem a condição de deficiência e ávidos pela diversificação de condições de acesso ao conhecimento escolar. Nesse sentido, a elaboração individualizada de atividades/planejamento para o público alvo da educação especial é uma ação importante e necessária, entretanto, acreditamos se estas adaptações forem pensadas no bojo do currículo comum aos demais estudantes, tornarem-se uma rica oportunidade para contemplar especificidades de outros estudantes.

Outro aspecto importante sob nossa ótica, a participação dos colegas na turma junto aos desafios pensados para determinados estudantes, pode sobremaneira ensiná-los sobre o trabalho colaborativo e apoio mútuo na/para realização das atividades escolares. Este ponto, quando fortalecido desde cedo, colabora à formação de gerações mais respeitosas e sensíveis ao trato da inclusão escolar sob diferentes frentes.

Outrossim, têm sido frequentes relatos de professores sobre o número expressivo de estudantes público da educação especial por turma. Desse modo, a ideia de um currículo específico para cada estudante, demandaria um esforço docente, talvez inatingível, fazendo-nos comprovar o desafio de estabelecer uma constante interlocução com o mesmo currículo da turma.

Quanto à remota possibilidade de secundarizar o acesso ao conhecimento e priorizar o currículo funcional para estes estudantes, demasiadamente nos ancoramos nas contribuições de Moreira (2005, p. 38), pois não basta entender o estudante excluído da escola como ser cultural "[...] há que se voltar a considerar mais rigorosamente os processos de selecionar, organizar e sistematizar os conhecimentos a serem ensinados e aprendidos na escola."

Sobre este último aspecto, consideramos a prevalência desse olhar na totalidade dos trabalhos localizados em ambas categorias - ampla e individualizada - identificadas em nosso estudo. Desse modo, o estudo revelou-se como importante para a reafirmação na indiscutível participação e capacidade dos estudantes público alvo da educação especial e o convite ao revisitar de nossas práticas, ou das futuras práticas, para aprofundar como tornar o currículo acessível a quaisquer estudantes, porque indubitavelmente permanece como tarefa da educação.

\section{Considerações Finais}

O propósito do presente texto foi fortalecido pela aquiescência de um construto teórico acerca do currículo escolar e deficiência e suas intersecções com o levantamento teórico advindo do período de 2015 à 2019. O decantado interesse no cerne da produção brasileira oriundo da BDTD, decorrente de pesquisa de IC com apoio do PCIN, acentuou a possibilidade de 
ampliação do objeto de estudo, o currículo escolar e a educação especial, sob diferentes perspectivas teórico, metodológica e epistemológicas.

As abordagens teóricas e históricas como principiam a introdução deste estudo revelaram-se importantes na convergência do entendimento sobre o necessário respeito às diferenças no espaço escolar. O estudo realçou a possibilidade de ampliação de pesquisas concernentes a um currículo comum e acessível a todos estudantes e suas reverberações nas práticas de ensino para turmas inevitavelmente heterogêneas, principalmente na concepção de deficiência basilar para o engendramento destas práticas.

Inegavelmente, a oportunidade da divulgação do estudo pode favorecer ao campo da inclusão do público alvo da educação especial, bem como inspirar futuras investigações e experiências para a garantia dessa inclusão escolar.

Há, sobremaneira, uma supremacia do trato curricular na inclusão de estudantes com deficiência, afinal muitos aspectos possuem grande articulação com o tema - recursos para o auxílio da aprendizagem; formação continuada para os professores e demais envolvidos com a inclusão; AEE para estudantes com necessidades específicas; planejamento e avaliação condizentes com os objetivos e possibilidades de participação de quaisquer estudantes; (con)formação de identidades/subjetividades de diferentes estudantes $-\mathrm{e}$, por isso, requerem grande atenção no bojo das práticas de ensino.

Do ponto de vista das condições de participação em turmas comuns de ensino, sem distanciar os estudantes com deficiência das propostas pedagógicas dirigidas aos demais os estudantes, é preciso aventar novas possibilidades porque, inconteste, podem oportunizar mudanças não apenas para quem possui a deficiência, afinal, outros estudantes também reclamam por aulas mais criativas e facilitadoras da aprendizagem.

O estudo possibilita o início de diálogo com outras pessoas interessadas no assunto e, com evidência, destaca a relevância da IC na apropriação de temáticas caras aos pesquisadores em formação. Do ponto de vista teórico e metodológico, acreditamos ser um ponto nevrálgico ao fortalecimento de pesquisas e contribuições com a área.

Ademais, o tema endossa sua importância pela via da convivência/contato com pessoas com deficiência em nosso cotidiano, e a imprescindibilidade de posicionamentos mais coerentes com o respeito e superação a qualquer tipo de preconceito e discriminação. Quanto à sua inserção em uma moldura mais ampla de possibilidade de divulgação e acesso, o estudo se estabelece como fundamental para a vida acadêmica do estudante e profissional de docentes no trabalho com quaisquer turmas, aspecto caro aos interessados no campo educacional.

Efetivamente, o estudo oportuniza identificar possibilidades de futuras análises, como o aprofundamento a ideia da flexibilização curricular e o subsequente horizonte teórico para diferentes professores, assim como suas intersecções para/na participação de pessoas com deficiência no espaço escolar, aspectos caros aos debates acadêmicos e sinalizadores de esforços para o desenvolvimento de novos trabalhos.

\section{Referências}

Aporta, A. P. (2015). Ensino de professores para o uso de instrução com tentativas discretas para crianças com Transtorno do Espectro Autista. Dissertação (Pós- Graduação) - Universidade Federal de São Carlos.

Araújo, M. A. de. (2019). Adaptações curriculares para alunos com deficiência intelectual: das concepções às práticas pedagógicas. Dissertação (Pós- Graduação Stricto Sensu em Educação) - Universidade Federal de Goiás.

Araújo, M. A. de. (2019). Práticas pedagógicas na educação infantil frente à acessibilidade curricular de crianças com síndrome de Down. Dissertação (PósGraduação em Educação) - Universidade Estadual Paulista.

Arroyo, M. G. (2007). Indagações sobre currículo - educandos e educadores: seus direitos e o currículo. Brasília: Ministério da Educação, Secretaria de educação básica.

Bachiega, A. G. (2018). Avaliação da aprendizagem em processo para nortear as aulas de matemática para alunos com deficiência intelectual. Dissertação (Pós- Graduação em Docência para a Educação Básica) - Universidade Estadual Paulista. 
Barbosa, M. O. (2018). Estudantes com Transtorno do Espectro do Autismo (TEA) na escola: desafios para a ação educativa compartilhada. Tese (PósGraduação em Educação Especial) - Universidade Federal de São Carlos.

Bardin, L. (2009). Análise de Conteúdo. Edições 70, LDA.

Bergamin, A. C. (2018). Enriquecimento curricular na classe comum a partir das necessidades de alunos com altas habilidades/superdotação. Dissertação (Pós- Graduação em Docência para a Educação Básica) - Universidade Estadual Paulista.

Belusso, R. (2017). Paisagens do atendimento educacional especializado. Dissertação (Pós- Graduação em Educação) - Universidade de Caxias do Sul.

Brasil. (1996). Ministério da Educação. Lei de Diretrizes e Bases da Educação Nacional.

Brasil. (1988). Constituição da República Federativa do Brasil. Imprensa Oficial.

Brasil. (2008). Ministério da Educação. Política Nacional de Educação Especial na perspectiva da Educação Inclusiva. MEC.

Brasil. (2015). Lei Brasileira de Inclusão da Pessoa com Deficiência (Estatuto da Pessoa com Deficiência). Brasília: Presidência da República.

Carvalho, L. C. \& Antunes, H. S. (2021). Garimpando obras: estado do conhecimento sobre formação permanente de professores, educação especial e docência inclusiva. Research, Society and Development, 10 (2), 1-12.

Carvalho, W. F. de. (2017). Terra-Mar: Litorais entre a socioeducação e a educação especial. Dissertação (Pós- Graduação em Educação) - Universidade Federal do Rio Grande do Sul.

Carvalho, R. E. (2008). Escola inclusiva: a reorganização do trabalho pedagógico. Mediação.

Costa, C. de M. (2015). Inclusão de estudantes com deficiência visual nas aulas de educação física: um estudo de caso. Dissertação (Pós- Graduação em Educação Especial) - Universidade Federal de São Carlos.

Diniz, D. (2007). O que é deficiência. Brasiliense.

Duarte, A. A. da S. (2018). Enriquecimento curricular para alunos com altas habilidades/superdotação no ensino médio: práticas de leitura. Dissertação (PósGraduação em Docência para a Educação Básica) - Universidade Estadual Paulista.

Effgen, A. P. S. (2011). Educação especial e currículo escolar: possibilidades nas práticas pedagógicas cotidianas. Dissertação (Mestrado em Educação). Universidade Federal do Espírito Santo.

Ferreira, M. E. C. \& Guimarães, M. (2003). Educação inclusiva. DP\&A.

Ferreira, N. S. de A. (2002). As pesquisas denominadas “estado da arte". Educação \& Sociedade, 23 (79), 257-272.

Filho, P. L. dos S. (2015). Escolarização de surdos no ensino médio em Natal/ RN: vendo e ouvindo vozes. Dissertação (Pós- Graduação em Educação) Universidade Federal do Rio Grande do Norte.

Fiorini, M. L. S., Deliberato, D. \& Manzini, E. J. (2013). Estratégias de ensino para alunos deficientes visuais: a Proposta Curricular do Estado de São Paulo. Motriz. Rio Claro, 19 (01), p. 62-73.

Flóro, L. F. D. (2016). Inclusão escolar, sala de recursos multifuncionais e currículo: tecendo aproximações. Dissertação (Pós- Graduação em Educação) Universidade de São Paulo.

Fonseca, K. A. (2014). Análise de adequações curriculares no Ensino Fundamental: subsídios para programas de pesquisa colaborativa na formação de professores. 2011. 124 f. Dissertação (Mestrado em Psicologia do Desenvolvimento e Aprendizagem) - Universidade Estadual Paulista.

Gavaldão, N. (2017). Acessibilidade a estudantes surdos na educação superior: análise de professores sobre o contexto pedagógico. Dissertação (PósGraduação em Educação) - Faculdade de Filosofia e Ciências da Universidade Estadual Paulista.

Glat, R. (2007). Educação Inclusiva: cultura e cotidiano escolar. 7Letras.

Gomes, N. L. (2007). Indagações sobre currículo: diversidade e currículo. Ministério da Educação, Secretaria de Educação Básica.

Guadagnini, L. (2018). Adaptação do currículo nas aulas de língua portuguesa para alunos com deficiência intelectual. Dissertação (Pós- Graduação e Educação Especial) - Universidade Federal de São Carlos.

Haas, C. (2016). "Isto é um jogo": imagens-narrativas do currículo, tempo e trajetórias escolares de estudantes com deficiência. Tese (Pós- Graduação em Educação) - Universidade Federal do Rio Grande do Sul.

Klein, M. \& Formozo, D. de P. (2009). Im/possibilidades na educação de surdos: discussões sobre currículo e diferença. Currículo sem Fronteiras, 9 (2), p. 212 225 .

Leite, L. P. \& Martins, S. E. S. de O. (2015). Educação, culturas e realidade social - A educação especial em tempos de educação inclusiva: dos aportes normativos aos aspectos operacionais. In: David, C. M., et al., (orgs). Desafios contemporâneos da educação [online]. Editora UNESP; São Paulo: Cultura Acadêmica, pp. 85-105. http://books.scielo.org/id/zt9xy/pdf/david-9788579836220-06.pdf

Lopes, E. (2010). Adequação curricular: um caminho para a inclusão do aluno com deficiência intelectual. Dissertação (Mestrado em Educação) - Universidade Estadual de Londrina.

Lopes, A. C. \& Macedo, E. (2011). Teorias de Currículo. Cortez. 
Luiz, N. M. (2018). Teorema de Pitágoras: uma proposta de ensino e aprendizagem para alunos deficientes visuais. Dissertação (Pós- Graduação em Ensino de Ciências Exatas) - Universidade Federal de São Carlos.

Machado, P. R. (2017). Práticas inclusivas para a escolarização do aluno com TGD: Desenvolvimento de uma cartilha paradidática ilustrada. Dissertação (PósGraduação em Docência para a Educação Básica) - Universidade Estadual Paulista.

Magalhães, R. de C. B. P. (2002). Reflexões sobre a diferença: uma introdução a educação especial. Demócrito Rocha/ Ed. UECE. p. 21 - 34

Marostega, V. L. (2015). Os Currículos de Formação de Professores para Surdos na UFSM: A Educação Especial como Campo de Saber (1962- 2010). Tese (Pós-Graduação em Educação). Universidade do Vale do Rio do Sinos.

Martins, A. T. (2017). Inclusão de estudantes com diferenças funcionais: a construção de um currículo cultural da Educação Física no Cieja. Dissertação (PósGraduação em Educação) - Universidade de São Paulo.

Mesquita, G. (2015). O processo de alfabetização de uma criança com deficiência intelectual no $1^{\circ}$ ano do ensino fundamental. Dissertação (Pós- Graduação em Educação) - Universidade Federal do Espírito Santo.

Minayo, M. C. de S. (org.). (2001). Pesquisa Social: Teoria, método e criatividade. (18a ed.), Vozes.

Monteiro, M. R. C. (2015). Educação Inclusiva e Implicações no Currículo Escolar: a invenção de outros processos de ensinar e aprender. Tese (Pós- Graduação em Educação) - Universidade Federal do Rio Grande do Sul.

Moreira, A. F. B. (2007). Indagações sobre currículo: currículo, conhecimento e cultura. - Brasília: Ministério da Educação, Secretaria de Educação Básica.

Moreira, A. F. B. (2005). A crise da teoria curricular crítica. In: COSTA, M. V. (Org.). O currículo nos limiares do contemporâneo. DP\&A, p. 11-32.

Moreira, A. F. B. \& Silva, T. T. da. (1995). Currículo, cultura e sociedade. (2a ed.), Revista Cortez.

Nunes, V. L. M. (2019). Concepção do professor do ensino regular sobre a inclusão de alunos com deficiência intelectual. Dissertação (Pós- Graduação em Educação) - Universidade Estadual Paulista.

Padilha, J. C. (2018). A mediação docente dos conceitos básicos da genética para alunos com deficiência intelectual. Dissertação (Pós- Graduação em Ensino de Educação Básica) - Universidade Federal de Goiás.

Paula, H. I. G. de. (2016). Adaptações curriculares e a inclusão educacional da pessoa em situação de deficiência: um estudo de caso em escolas públicas localizadas no município de Belém/ PA. Dissertação (Pós- Graduação em Educação) - Universidade Federal do Pará.

Paulino, V. C. (2017). Efeitos do coensino na mediação pedagógica para estudantes com cegueira congênita. Tese (Pós- Graduação em Educação Especial) Universidade Federal de São Carlos.

Pio, D. N. A. (2018). Currículo e diferença na educação especial em uma perspectiva inclusiva. Dissertação (Mestrado em Educação) - Universidade Federal de Goiás.

Sacristán, J. G. (2000). O currículo: uma reflexão sobre a prática. Trad. Ernani Rosa. (3a ed.), Artmed.

Sacristán, J. G. (1998). O currículo: os conteúdos do ensino ou uma análise da prática? In: P. G., A. I.; Sacristán, J. G. Compreender e transformar o ensino. Artmed. 119-148.

Santos, F. J. da S. (2017). Escolarização e currículo: considerações no campo das deficiências. Dissertação (Pós- Graduação em Educação) - Universidade de São Paulo.

Scherer, R. P. (2015). Cada um aprende de um jeito: das adaptações às flexibilizações curriculares. Dissertação (Pós- Graduação em Educação) -Universidade do Vale do Rio dos Sinos.

Silva, F. de C. T. (2010). Entre o Processo Civilizador e a Gestão Controlada do Currículo: a escola inclusiva "dos deficientes". Currículo sem Fronteiras, 10 (2), 214-227.

Soares, M. T. N. (2015). Currículo escolar e inclusão de estudantes com deficiência: diálogos com uma escola pública. 314 f. Tese (Doutorado em Educação) - Universidade Federal do Rio Grande do Norte.

Teixeira, K. C. (2016). A criança surda na educação infantil: contribuições para pensar a educação bilíngue e o atendimento educacional especializado. Tese (Pós- Graduação em Educação) - Universidade Federal do Espírito Santo.

Valera, J. R. (2015). Deficiência intelectual e adaptação curricular sob o olhar de teses e dissertações. Dissertação (Pós- Graduação em Educação Escolar) Universidade de Ciências e Letras da Universidade Estadual Paulista.

Vieira, A. B. (2012). Currículo e Educação Especial: as ações da escola a partir dos diálogos cotidianos. 2012. 327 f. Tese (Doutorado em Educação) Universidade Federal Espírito Santo.

Zanato, C. B. \& Gimenez, R. (2017). Educação Inclusiva: um olhar sobre as adaptações curriculares. Revista @mbienteeducação, 10 (2), 289-303. http://publicacoes.unicid.edu.br/index.php/ambienteeducacao/article/view/30

Zerbato, A. P. (2018). Desenho universal para aprendizagem na perspectiva da inclusão escolar: potencialidades e limites de uma formação colaborativa. Tese (Pós- Graduação em Educação Especial) - Universidade Federal de São Carlos. 